\title{
ANÁLISE COMPARATIVA DOS RELATÓRIOS SOCIOAMBIENTAIS DE 2013 E 2016 DE EMPRESAS PARTICIPANTES DO PROGRAMA "EM BOA COMPANHIA"
}

\author{
COMPARATIVE ANALYSIS OF THE SOCIAL ENVIRONMENTAL REPORTS OF \\ 2013 AND 2016 OF COMPANIES PARTICIPATING IN THE PROGRAM "IN GOOD \\ COMPANY"
}
Deisy Cristina Corrêa Igarashi ${ }^{1}$, Adriel da Costa Benati ${ }^{2}$, Flávia Mayara Segate ${ }^{1}$, Bárbara Johann Borges ${ }^{1}, e$ Wagner Igarashi ${ }^{3}$
1 Universidade Estadual de Maringá, Programa de Pós-graduação em Administração, Brasil, e-mail: deisyigarashi@gmail.com, flaviasegate@gmail.com, barbarajohannb@gmail.com
2 Universidade Universidade Estadual de Maringá, Departamento de Ciências Contábeis, Brasil, e- mail: adriel_670@hotmail.com

3 Universidade Estadual de Maringá, Departamento de Informática, Brasil, e-mail: wigarash@gmail.com

A R T I C LE IN F O

Article history:

Received 2019-12-20

Accepted 2020-01-10

Available online 2020-02-20
Palavras chave: "Em Boa Companhia". ISE. Eixos. Socioambiental. BM\&FBovespa.

Keywords: "In Good Company". ISE. Axes. Socioenvironmental. BM\&FBovespa.

RESUMO. Com a crescente demanda por ações sociais e ambientais o montante de empresas que apresentam relatórios com estas atividades e seus resultados vem ganhando destaque. A partir do exposto este estudo tem por objetivo identificar se há alinhamento entre os eixos temáticos do programa "Em Boa Companhia" da BM\&FBovespa com as informações socioambientais divulgadas pelas empresas que participam do programa. Sendo aplicado o estudo nas empresas Cia. Suzano de Papel e Celulose, Klabin S/A e Duratex S.A., nas quais, foi identificado que comparando o ano de 2013 e 2016, houve aumento da frente de atuação vinculada ao eixo de "Planeta" em todas as empresas estudadas. Quanto ao eixo "Pessoas", no ano de 2016 as três empresas apresentavam atuação em uma das frentes, já em relação ao eixo "Prosperidade", identificou-se que apenas a Cia. Suzano de Papel e Celulose aumentou a atuação junto às frentes de ação. No eixo de "Parceria" a Cia. Suzano de Papel e Celulose deixou de apresentar ações no ano de 2016, enquanto a Klabin S/A passou a ter ações vinculadas ao eixo e a Duratex S.A. manteve-se atuando em uma das frentes. Não foram identificadas atividades vinculadas ao eixo de "Paz" durante 0 estudo.

ABSTRACT. With the increasing demand for social and environmental actions, the number of companies reporting on these activities and their results has been gaining prominence. From the foregoing, this study aims to identify if there is alignment between the thematic axes of the "In Good Company" program of BM \& FBovespa with the socioenvironmental information disclosed by the companies that participate in the program. The study was applied to companies Suzano de Papel e Celulose, Klabin S/A and Duratex SA, in which it was identified that comparing the year of 2013 and 2016, there was an increase in the performance front linked to the "Planet" axis in all the companies studied. As for the "People" axis, in 2016, the three companies were active on one of the fronts, already in relation to the "Prosperity" axis, it was identified that only Suzano Papel e Celulose action. In the "Partnership" axis, Suzano de Papel e Celulose ceased to be a shareholder in 2016, while Klabin S/A started to have shares linked to the axis and Duratex SA continued to operate on one of the fronts, not activities related to the "Peace" axis were identified during the study. 


\section{Introdução}

A crescente demanda por adoção de políticas sociais e ambientais está pautada na busca por garantir a importância de ações que promovam a manutenção do meio ambiente em prol da continuidade de vida no planeta (OLIVEIRA, CARDOSO; 2015). Deste modo, temas a respeito de ações socioambientais realizadas por empresas são discutidos em âmbito mundial. Tornando crescente o interesse de uma parcela de stakeholders por informações que explicitem as práticas de tais ações (OLIVEIRA, CARDOSO, 2015).

Karkotli e Aragão (2005) estudaram aspectos históricos que motivaram o desenvolvimento de práticas vinculadas às ações de responsabilidade social. Neste estudo destacam-se três pontos: Carnigie, o fundador do conglomerado U.S. Steel Corporation em 1899 na França, começou a inserir os princípios de caridade e custódia junto à sociedade; Ford, fundador da Ford Motor Company em 1919 nos Estados Unidos, reverteu parte dos lucros para aumento de salários e constituição de fundo de reserva; e, por fim, em 1960 as empresas passaram a ter foco em prestar informações ao público sobre suas atividades no campo social, devido a repercussões sobre a guerra do Vietnã (KARKOTLI, ARAGÃO, 2005).

Estes três momentos se destacam por terem desencadeado a prática de ações socioambientais segmentada em três agrupamentos (interno, externo e ambiental), os quais são foco das empresas ao evidenciarem suas ações de forma voluntária nos relatórios publicados, ou junto aos seus sites (TREVISAN, 2002, OLIVEIRA, 2005, BRAGATO, et al., 2008, CLARO, CLARO, LUCCI, 2009).

Além disso, estes agrupamentos compõem propostas e modelos reconhecidos no âmbito empresarial, governamental e de pesquisa acerca do tema, inclusive em modelos como os propostos pelo Instituto Brasileiro de Análises Sociais e Econômicas (Ibase), Instituto Ethos, e Global Reporting Initiative (GRI); em alguns casos foram propostos outros agrupamentos (SOUZA FILHO, DA SILVA, 2008).

Diversas empresas ganharam destaque com práticas de ação social, como, por exemplo, aquelas que: compõem a carteira do Índice de Sustentabilidade Empresarial (ISE); compõem a carteira de Índice Carbono Eficiente (ICO2); apoiam o Instituto Akatu; são associadas ao Instituto Ethos; apoiam a Bolsa de Valores Socioambientais (BVSA); ou participam do programa "Em Boa Companhia" da BM\&FBovespa. (COLARES et al., 2012, LANA et al., 2011, ORELLANO, QUIOTA, 2011, DOMENICO et al., 2015). Para esta pesquisa, foi selecionado o programa "Em Boa Companhia" da BM\&FBovespa.

O programa "Em Boa Companhia" que também é conhecido como Bolsa de Valores Socioambientais (BVSA) foi instituído pela BM\&FBovespa, buscando captar recursos com vistas a serem investidos em projetos socioambientais do país, assim a BVSA proporciona a 
interação entre investidores que têm 0 interesse em contribuir com aspectos socioambientais, e pessoas físicas ou jurídicas que necessitam de aporte financeiro para execução de projetos socioambientais (BVSA, 2018).

Macedo e Cípola (2009) observam que há crescente demanda de informações que explicitem dados sobre os produtos e serviços oferecidos no sentido de minimizar ou evitar danos ambientais, melhorar o tratamento dispensando aos colaboradores e seus afetos em ações que extrapolem a remuneração e os benefícios devidos por força de lei e à sociedade como um todo, devido à inserção da instituição junto ao meio ambiente e às comunidades com as quais está inserida. Tais informações têm sido publicadas em relatórios de caráter voluntário, nominados, por exemplo, como: Balanço Social, relatório de sustentabilidade, podendo ainda compor relatórios mais abrangentes, e permear os relatórios da administração (NEU, WARSAME, PEDWELL, 1998, OLIVEIRA et al., 2010, COLARES et al., 2012; ORELLANO, QUIOTA, 2011; CAMPOS et al., 2013).

Estas demonstrações que têm divulgado informações de cunho socioambiental nem sempre representam um conjunto de informações econômicas e sociais que possibilitam identificar a atuação efetiva da instituição em benefício da sociedade (OLIVEIRA, GOUVÊA, 2010). Além disso, há de se considerar que caso a empresa opte por um modelo em específico, seria necessário que a divulgação fosse fiel ao modelo operacionalizado, ou seja, contemplar ao menos os agrupamentos macro previstos no modelo em questão, o que na prática das instituições podem não refletir a realidade, uma vez que os relatórios são utilizados, principalmente, como instrumento de reforço à imagem das organizações (ANDRADE, GOSLING, XAVIER, 2010).

Deste modo espera-se que as empresas que participem do programa "Em boa Companhia" apresentem alinhamento entre as ações socioambientais descritas em seus relatórios, aos eixos temáticos que estão previstos pela BVSA, porém alguns problemas são relatados em pesquisas a respeito do alinhamento das divulgações de práticas de ações socioambientais, tais como: divulgação incompleta das informações, relatórios mal estruturados, ou que assumem modelos específicos que ao serem formalizados não expressam as informações que compõe o modelo utilizado, relatórios de caráter descritivo, os quais não possibilitam identificar valores investidos, ou número de pessoas, comunidades, integrantes beneficiados, dentre outros pontos (PINTO, RIBEIRO, 2004). Portanto, apesar de o tema estar sendo discutido há décadas, a divulgação de informações vinculadas as ações socioambientais não apresentam consenso (PINTO, RIBEIRO, 2004).

Neste sentido, há uma questão a ser explorada: como se configura o alinhamento entre os eixos temáticos do programa "Em Boa Companhia" da BM\&FBovespa com as informações socioambientais divulgadas pelas empresas que participam do programa? A partir do exposto este estudo tem por objetivo identificar se há alinhamento entre os eixos temáticos do programa "Em Boa Companhia" da BM\&FBovespa com as informações 
socioambientais divulgadas pelas empresas que participam do programa, por meio do Índice de Sustentabilidade Empresarial (ISE).

O estudo justifica-se pela importância de analisar as informações relacionadas à responsabilidade social dessas empresas, visto que "Em Boa Companhia" - Programa de Sustentabilidade com Empresas é um programa da BM\&FBovespa que tem o objetivo de comprometer as empresas com a temática da sustentabilidade, preparando-as para o novo contexto empresarial, no qual os fatores sociais e ambientais são tão importantes quanto os econômico-financeiros (BM\&FBOVESPA, 2018).

A pesquisa se limita a investigar empresas que pertenceram ao programa "Em Boa Companhia" da BM\&FBovespa e que compunham a carteira do (ISE) entre 2013 e 2016. Foram objeto de análise as empresas Duratex S.A., Suzano Papel e Celulose e Klabin através dos relatórios descritivos de caráter socioambiental divulgados em 2013 e 2016.

\section{Fundamentação teórica}

\subsection{Divulgação das informações de caráter social}

A ampla discussão a respeito de temas como responsabilidade social e ações socioambientais têm fomentado práticas vinculadas à divulgação de relatórios que disseminem tais informações, ainda que este tipo de relatório não seja obrigatório (PINTO, RIBEIRO, 2004). Além disso, em muitos casos, as empresas os apresentam com o objetivo de marketing, entretanto a maioria das ações realizadas e divulgadas, independente do objetivo que as propiciaram, beneficia funcionários, comunidade e o meio ambiente com a qual a empresa atua (OLIVEIRA, 2005). Oliveira, Gouvêa (2010) corroboram esta percepção ao identificarem que as empresas não vinculam suas marcas a temas e ações sociais, na intensidade necessária para que os consumidores a conheçam e lembrem-se disso. Percepção que está alinhada aos resultados de Deng, Keng e Low (2013) que ao pesquisarem empresas americanas identificaram que o mercado não valoriza práticas socioambientais de imediato.

Por outro lado, Pastrana e Sriramesh (2014) destacam que práticas vinculadas a ações socioambientais na Colômbia são revertidos em benefício mais rapidamente às empresas se direcionadas à cultura organizacional, ao bem-estar de funcionários e às relações com os clientes. Pinto e Lara (2003) obtêm resultados parecidos ao estudar empresas brasileiras.

Apesar de as motivações que conduzem aos investimentos e às divulgações de ações socioambientais serem movidos por interesses distintos, diversas pesquisas indicam ser crescente o número de empresas que têm realizado tal prática, assim como o fato de estas práticas não se comprovarem como efetivas na busca por resultados financeiros maiores ou fidelização de clientes ou parceiros (OLIVEIRA, GOUVÊA, 2010; PINTO, LARA, 
2003; BRAGATO, GRAZIANO, SIQUEIRA, SPERS, 2008; ORELLANO, QUIOTA, 2011).

Ademais, pesquisas que enfocaram empresas atuantes em ações socioambientais, como as participantes do ISE e as não participantes, empresas que atuam em segmentos de externalidade negativa junto à sociedade (fumo, bebida, exploração mineral, barragens, armas) e empresas oriundas de segmentos menos agressivos, apresentam discrepâncias em seus resultados como, por exemplo, empresas não participantes e ou oriundas de segmentos menos agressivos que apresentam em média investimentos sociais maiores do que as empresas do ISE, e ou das que atuam em segmentos de comprovada externalidade negativa (MILANI FILHO, 2008; BUFONI, FERREIRA, MUNIZ, 2009; CALIXTO, BARBOSA, LIMA, 2007; COLARES et al., 2012).

Uma ação que poderia auxiliar a melhor compreender o comportamento das empresas em relação às práticas socioambientais talvez seja a identificada por Oliveira (2005) ao concluir que os relatórios que apresentam informações socioambientais deveriam passar por um processo de normatização voluntária para que não percam legitimidade. Solução que estaria alinhada a percepção de Aquino e Santana (1992) ao complementar que a divulgação deveria ser realizada de modo a proporcionar fácil entendimento, a fim de que a parte interessada compreenda de imediato o que está sendo comunicado.

Adams, Will e Roberts (1998) ao pesquisar empresas europeias identificaram que os seguintes fatores influenciam as divulgações socioambientais: porte, segmento de atuação, país de origem, localidade em que está instalada e os padrões de relatórios utilizado.

Apesar das discrepâncias que podem ser oriundas de fatores que influenciam as divulgações socioambientais (porte, segmento de atuação, origem, localidade, padrões de relatórios) Santolin e Frey (2005), Carneiro, De Luca e Oliveira (2008), Bragato et al. (2008), Oliveira e Gouvêa (2010), Igarashi et al. (2010) identificaram em seus estudos que empresas distintas em termos de: porte, segmento, área atuação, localidade e relatório analisado (período, abordagem, ferramenta de pesquisa) apresentaram informações que em maior proporção estão direcionadas a atender as necessidade de seus funcionários, seguido por programas com aspectos sociais externos (carência social).

Além disso, Bragato et al. (2008) destacam que as ações sociais estavam concentradas nas áreas educacional e ambiental e, em segundo plano, ações relacionadas à cultura, ao esporte e à saúde. Por outro lado, Galego-Álvarez, Formigoni e Antunes (2014) identificaram que as práticas ambientais estão mais relacionadas às empresas localizadas no Norte do Brasil, enquanto que as práticas sociais e comunitárias estão ligadas às empresas localizadas nas regiões Sul e Nordeste do país.

\subsection{ISE}

O Índice de Sustentabilidade Empresarial BM\&FBOVESPA (ISE) objetiva demonstrar o retorno de uma carteira de ações comprometidas com o desenvolvimento sustentável, 
suas práticas e alinhamento estratégico, além de atuar como indutor das boas práticas no meio empresarial brasileiro (ISE, 2018).

O ISE foi o quarto índice de gestão sustentável de ações visando demonstrar a atuação do mercado a partir de uma carteira de empresas que adotam princípios de gestão sustentável (BM\&FBOVESPA, 2018). O primeiro índice criado, desse modelo, foi o Dow Jones Sustainability Indexes (DJSI), de 1999, em Nova lorque, em seguida o FTSE4Good, de Londres, foi criado em 2001; em terceiro, 2003, o JSE, de Johanesburgo, África do Sul. Em primeiro de dezembro de 2005, o Brasil apresentou, em São Paulo, o Índice de Sustentabilidade Empresarial, com 34 ações de 28 empresas classificadas como as mais avançadas nas práticas de sustentabilidade empresarial (BM\&FBOVESPA, 2018).

Os seguintes itens são critérios para a inclusão no ISE: estar entre os ativos elegíveis que nas três carteiras anteriores ocuparam uma das 200 primeiras posições do Índice de Negociabilidade da BM\&FBOVESPA, assim como, ter participação em pregão de $50 \%$ (cinquenta por cento) no período de 3 (três) carteiras, não possuir ativos cuja cotação seja inferior a $R \$ 1,00$, atender aos critérios de sustentabilidade determinados pelo Conselho Deliberativo do ISE (ISE, 2018).

São critérios de exclusão da carteira do ISE, as carteiras que deixarem de atender a qualquer um dos critérios de inclusão, que passem a ser classificados em situação de recuperação judicial ou extrajudicial e regime especial de administração temporária (BM\&FBOVESPA, 2018). Além disso, caso o desempenho sustentável tenha sofrido alterações significantes devido a fatos ocorridos durante a vigência da carteira, os ativos serão excluídos a qualquer momento por deliberação do CISE (BM\&FBOVESPA, 2018).

\section{Método de Pesquisa}

Com o intuito de responder o problema proposto nesta pesquisa, esta se caracteriza como descritiva, que busca descrever as características de determinada população ou fenômeno e busca estabelecer relações entre as variáveis (DIEHL; TATIM, 2004). Triviños (1987) complementa que o estudo descritivo busca "descrever 'com exatidão' os fatos e fenômenos de determinada realidade". Especificamente, busca-se descrever se as informações divulgadas pelas empresas selecionadas como objeto de estudo em seus relatórios miméticos, com foco específico nas atividades desenvolvidas com foco em ações externas, apresentam alinhamento com o programa "em boa companhia" também conhecido como BVSA.

O programa em 2007 passou a adotar cinco eixos temáticos (planeta, pessoas, prosperidade, parceria e paz), a partir de 2016, alinhados ao Programa das Nações Unidas para o Desenvolvimento (PNUD), os quais estão vinculados à dezessete frentes de atuação (BVSA, 2016), a saber: erradicação da pobreza, erradicação da fome, saúde de qualidade, 
educação de qualidade, igualdade de gênero, água limpa e saneamento, energias renováveis, empregos dignos e crescimento econômico, inovação e infraestrutura, redução das desigualdades, cidades e comunidades sustentáveis, consumo responsável, combate as mudanças climáticas, vida de baixo da água, vida sobre a terra, paz e justiça e parcerias pelas metas. Para esta pesquisa optou-se por analisar os relatórios com enfoque apenas nas ações externas, que apresentam enfoque em ações realizadas a fim de gerar benefícios extensivos à sociedade como um todo, e não para públicos especificamente vinculados às empresas.

A população de estudo ( 3 empresas) compreendeu as empresas que fazem parte do programa "em boa companhia", e que estavam listadas no Índice de Sustentabilidade Empresarial (ISE) em 2016, sendo: Suzano Papel e Celulose, Klabin e Duratex, que publicaram relatórios de caráter socioambiental em 2013 e 2016. A pesquisa conta com corte seccional, realizado em dois momentos (relatórios divulgados em 2013 e 2016).

Quanto às ferramentas de intervenção, utiliza-se pesquisa documental que permite que o pesquisador reúna uma grande quantidade de informações sobre o objeto em estudo (TRIVINÕS, 1987). Configuraram-se como documentos de interesse informações disponibilizadas junto aos sites das empresas em estudo, bem como do BVSA, BM\&FBovespa.

\section{Análise de Dados}

Após a coleta dos dados junto aos Relatórios Socioambientais, observou-se em um primeiro momento a frequência dos indicadores presentes nos relatórios de 2013 e 2016 (gráfico 1). Em 2013, os totalizadores dos indicadores das frentes de atuação do ISE em uma das empresas analisadas encontram-se iguais, havendo aumento de frentes identificadas em duas das três empresas, no ano de 2016. 


\section{Gráfico 1 - Demonstrativo da frequência das frentes de atuação do ISE}

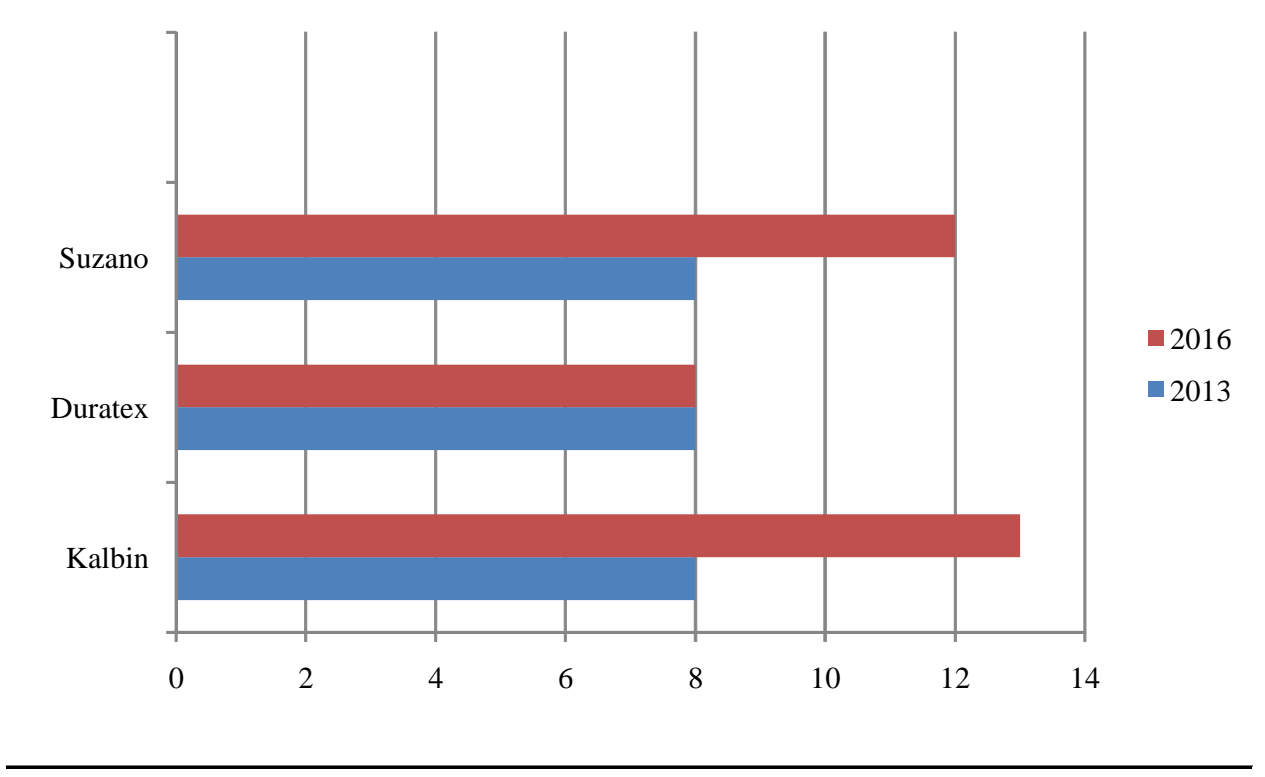

Fonte: Dados da Pesquisa

No ano de 2013 observa-se a semelhança entre na quantidade de frentes de atuação abordadas pelas empresas analisadas, tendo cada empresa apresentado oito delas. Em 2016 tem-se um aumento de abordagens, de oito para treze, na empresa Klabin S/A e de oito para doze na Cia. Suzano de Papel e Celulose, sem mudanças, no que tange a quantidade de frentes do ISE abordadas, na Duratex S.A.

Ao analisar a frequência dos eixos de ações socioambientais do ISE (quadro 1), identifica-se que, no ano de 2013, a empresa Duratex apresenta maior abrangência dos eixos trabalhados pelo ISE, estando presente quatros das cinco vertentes, enquanto as empresas Suzano e Klabin apresentam ações em três e duas vertentes, respectivamente.

Quadro 1 - Frequência de atuação nos eixos do ISE.

\begin{tabular}{|c|c|c|c|c|c|c|}
\hline \multirow{2}{*}{ EIXOS } & \multicolumn{2}{|c|}{ Suzano } & \multicolumn{2}{c|}{ Duratex } & \multicolumn{2}{c|}{ Klabin } \\
\cline { 2 - 7 } & $\mathbf{2 0 1 3}$ & $\mathbf{2 0 1 6}$ & $\mathbf{2 0 1 3}$ & $\mathbf{2 0 1 6}$ & $\mathbf{2 0 1 3}$ & $\mathbf{2 0 1 6}$ \\
\hline Planeta & 1 & 1 & 1 & 1 & 1 & 1 \\
\hline Pessoas & 0 & 1 & 1 & 1 & 0 & 1 \\
\hline Prosperidade & 1 & 1 & 1 & 1 & 1 & 1 \\
\hline Parceria & 1 & 0 & 1 & 1 & 0 & 1 \\
\hline Paz & 0 & 0 & 0 & 0 & 0 & 0 \\
\hline Total & 3 & 3 & 4 & 4 & 2 & 4 \\
\hline
\end{tabular}

Fonte: Dados da Pesquisa

Ao se analisar individualmente a Cia. Suzano de Papel e Celulose, nas vertentes de atuação do eixo de "Planeta", do ISE, verifica-se a evolução das frentes abordadas em 2013 em comparação com 2016 (quadro 2). 
Quadro 2 - Frequência da atuação da empresa

\begin{tabular}{|c|c|c|c|c|c|c|c|}
\hline \multirow{2}{*}{ 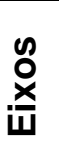 } & \multirow{2}{*}{ Frentes de atuação } & \multicolumn{2}{|c|}{ Suzano } & \multicolumn{2}{|c|}{ Duratex } & \multicolumn{2}{|c|}{ Klabin } \\
\hline & & 2013 & 2013 & 2013 & 2016 & 2013 & 2016 \\
\hline \multirow{8}{*}{ 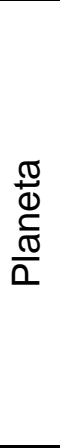 } & Água limpa e saneamento & 1 & - & - & - & 1 & 1 \\
\hline & Energias renováveis & 1 & 1 & 1 & 1 & 1 & 1 \\
\hline & $\begin{array}{l}\text { Cidades e comunidades } \\
\text { sustentáveis }\end{array}$ & - & - & - & - & - & 1 \\
\hline & Consumo responsável & 1 & 1 & 1 & 1 & 1 & 1 \\
\hline & Combate as mudanças climáticas & - & 1 & 1 & 1 & 1 & 1 \\
\hline & Vida de baixo da água & 1 & - & - & - & - & 1 \\
\hline & Vida sobre a terra & 1 & - & - & 1 & - & 1 \\
\hline & Frequência & 5 & 3 & 3 & 4 & 4 & 7 \\
\hline \multirow{4}{*}{$\begin{array}{l}\mathscr{D} \\
\mathbb{0} \\
\mathscr{D} \\
\mathscr{D} \\
0\end{array}$} & Erradicação da pobreza & - & - & - & - & - & 1 \\
\hline & Erradicação da fome & - & 1 & 1 & - & - & - \\
\hline & Igualdade de gênero & - & - & - & 1 & - & - \\
\hline & Frequência & - & 1 & 1 & 1 & - & 1 \\
\hline \multirow{6}{*}{\begin{tabular}{l}
$\frac{0}{0}$ \\
$\frac{\pi}{0}$ \\
$\frac{0}{0}$ \\
$\frac{0}{0}$ \\
\hdashline 0 \\
$\frac{0}{0}$ \\
0
\end{tabular}} & $\begin{array}{l}\text { Empregos dignos e crescimento } \\
\text { econômico }\end{array}$ & 1 & 1 & 1 & 1 & - & 1 \\
\hline & Redução das desigualdades & 1 & - & - & - & 1 & - \\
\hline & Saúde de qualidade & - & 1 & 1 & - & 1 & 1 \\
\hline & Educação de qualidade & - & 1 & 1 & 1 & 1 & 1 \\
\hline & Inovação e infraestrutura & - & - & - & - & 1 & 1 \\
\hline & Frequência & 2 & 3 & 3 & 2 & 4 & 4 \\
\hline \multirow{2}{*}{ 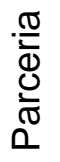 } & Parcerias pelas metas & 1 & 1 & 1 & 1 & - & 1 \\
\hline & Frequência & 1 & 1 & 1 & 1 & - & 1 \\
\hline \multirow{3}{*}{ న్ } & Paz e justiça & - & - & - & - & - & - \\
\hline & Frequência & - & - & - & - & - & - \\
\hline & Total & 8 & 8 & 8 & 8 & 8 & 13 \\
\hline
\end{tabular}

Fonte: Dados da Pesquisa

Ao se analisar a Suzano, observa-se no Eixo "Planeta" que de 2013 para 2016, foram iniciadas ações vinculadas à "Cidade e comunidades sustentáveis" e "Combate a mudanças climáticas", enquanto a frente de "Consumo responsável" deixou de estar presente no Relatório Socioambiental de 2016.

No eixo de "Pessoas", do ISE, verificou-se a evolução das frentes abordadas em 2013 em comparação com 2016, sendo que em 2013 não haviam ações vinculadas a esse eixo no Relatório Socioambiental. A Cia. Suzano passou a exercer ações vinculadas ao eixo de "Pessoas" no ano de 2016, na frente de "Igualdade de gênero", sendo que no ano de 2013 não houveram atividades destinadas a esse eixo.

Por sua vez, no eixo de "Prosperidade" da Cia. Suzano de Papel e Celulose, verificase a evolução das frentes abordadas em 2013 em comparação com 2016, no qual apenas duas das cinco frentes de ação eram exercidas, para que em 2016 haja atuação em todas 
as frentes do eixo de "Prosperidade". Ainda neste eixo, a empresa implementou ações vinculadas à "Saúde de qualidade", "Educação de qualidade" e "Inovação e infraestrutura", enquanto foram mantidas as ações de "Emprego digno e crescimento econômico" e "Redução das desigualdades" exercidas em 2013.

Com relação ao eixo de "Parceria", do ISE, verifica-se uma regressão, pois a empresa deixou de exercer ações vinculadas a "Parcerias e metas" em 2016. Cabe observar que o eixo "Paz" não apresentou movimentação nos anos analisados.

Analisando a Duratex S.A. (quadro 2), nas frentes de atuação do eixo de "Planeta", do ISE, verifica-se uma evolução. Em 2013 eram exercidas ações em três das sete frentes, passando a realizar atividades em quatro frentes no ano de 2016. Foram iniciadas ações vinculadas a "Vida sobre a terra", enquanto as frentes de "Energia renováveis", "Consumo responsável" e "Combate as mudanças climáticas" continuaram presentes no Relatório Socioambiental de 2016.

Analisando as frentes de atuação do eixo de "Pessoas", do ISE, na Duratex S.A., verifica-se a alteração das frentes abordadas em 2013 em comparação com 2016. No ano de 2013 as ações eram vinculadas à frente de "erradicação da fome", ao passo que em 2016 passou a se atuar na frente de "Igualdade de gênero".

No eixo de "Prosperidade" verificou-se uma redução das frentes abordadas, das cinco frentes de ação exercidas em 2013, três (Empregos dignos e crescimento econômico, saúde de qualidade, e educação de qualidade), enquanto que em 2016 a empresa passou a exercer somente duas frentes, deixando de atuar na frente de "Saúde de qualidade".

No eixo de "Parceria", do ISE, verifica-se que não houveram diminuições das ações no eixo, nos anos de 2013 e 2016. A Duratex, no que tange a frente de atuação de "Parceria pelas metas", manteve a presença de ações nos anos de 2016 e 2013.

Assim como a Suzano, a Duratex não apresentou movimentação nos anos analisados no eixo "Paz".

Por sua vez a Klabin S/A (quadro 2) nas frentes de atuação do eixo de "Planeta", do ISE, verifica-se evolução de 2013 para 2016 em 3 frentes abordadas. O Eixo de "Planeta" da Klabin apresentou como evolução as ações vinculadas à "Cidade e comunidades sustentáveis", "Vida de baixo da água" e "Vida sobre a terra".

Analisando as frentes de atuação do eixo de "Pessoas", do ISE, na Klabin S/A, verifica-se que em 2016, passa a haver ações em uma das frentes de atuação, a qual não era realizada em 2013. Deste modo a empresa em 2016 passa a atuar na frente de "Erradicação da pobreza".

Observando a presença de ações no eixo de "Prosperidade" da Klabin verifica-se a alteração das frentes abordadas em 2013 em comparação com 2016. Sendo mantidas 3 frentes de atuação e uma diferente em cada período. Em 2013 observou-se ações exercidas na frente de atuação "Redução da desigualdade" que deixou de estar presente no relatório 
socioambiental em 2016. Em 2016 a empresa passou a apresentar atuação na frente de "Emprego digno e crescimento econômico", a qual não era atuante em 2013.

Com relação as frentes de atuação do eixo de "Parceria", do ISE, verifica-se que em 2016, foram adotadas ações junto à vertente de "Parcerias pela metas", a quais não eram exercidas em 2013. Por fim o eixo de operação nominado de "Paz", com frente de atuação de "Paz e justiça", não se encontra descrito nos relatórios socioambientais, da empresa analisada, assim como nas empresas anteriores.

\section{Considerações Finais}

Em relação ao objetivo de identificar se há alinhamento entre os eixos temáticos do programa "Em Boa Companhia" da BM\&FBovespa com as informações socioambientais divulgadas pelas empresas que participam do programa, observou-se a existência de informações vinculadas às frentes de atuação, dos eixos do programa, nos relatórios socioambientais divulgados em 2013 e 2016.

As empresas analisadas apresentaram aumento de frente de atuação em seus relatórios socioambientais, sendo esse aumento visível em relação ao eixo de "Planeta". Em 2013 na Cia. Suzano de Papel e Celulose identificou-se a presença de atividades em cinco das oito frentes de atuação do eixo "Planeta", aumentando para seis em 2016, enquanto a atuação da Duratex S.A. no eixo "Planeta" era em três frentes em 2013 e passou para quatro em 2016. Já a empresa Klabin S.A. apresentou ações em quatro frentes do eixo "Planeta", em 2013 passando para sete frentes em 2016.

A Cia. Suzano de Papel e Celulose demonstrou atuações, no eixo de "Planeta" de $71 \%$ em 2013 , evoluindo para $86 \%$ em 2014. No eixo "Pessoas" a participação foi de $0 \%$ para 33\%, de 2013 para 2016, no eixo de "Prosperidade" foi de 40\% para 100\% do ano de 2013 para 2016. Por outro lado, quanto ao eixo "Parceria" em 2013 havia 100\% de atuação, enquanto em 2016 não houveram ações vinculadas, e o eixo de "Paz" manteve-se com 0\% de atuação em ambos os anos. A Duratex S.A., nos anos de 2013 e 2016 apresentou aumentos no eixo de "Planeta", onde a participação foi de $43 \%$ para $57 \%$, já o eixo de "Prosperidade" houve uma redução onde a participação foi de $60 \%$ para $40 \%$. Os eixos de "Pessoas" e "Parceria", permaneceram com, respectivamente, 33\% e 100\%, sem atuação no eixo de "Paz". A Klabin S.A. passou a apresentar presença em 100\% do eixo de "Planeta" enquanto em 2013 era de 57\%, no eixo de "Pessoas" houve aumento de 0\% em 2013 para 33\% em 2016, foi mantida a atuação de 80\% no eixo de "Prosperidade", apresentou aumento de 0\% em 2013 para 100\% em 2016 no eixo de "Parceira", e não houve atuação no eixo de "paz", em ambos os anos.

Para estudos futuros, recomenda-se que o estudo seja realizado, abrangendo todas as empresas da carteira do ISE, dos anos analisados neste estudo, de modo a identificar 
variações conforme a atuação das empresas. Também pode-se analisar relatórios socioambientais em mais de dois períodos, de modo a visar a evolução periódica da presença de ações vinculadas aos eixos do "Em Boa Companhia".

\section{Referências}

ADAMS, CAROL A., HILL, Wan-Ying and ROBERTS, Clare B. Corporate social reporting practices in Western Europe: legitimating corporate behavior? The British Accounting Review. London, vol.30, n.1, p.1 - 21, mar. 1998. DOI: https://doi.org/10.1006/bare.1997.0060.

ANDRADE, Marcelo Aureliano Monteiro de; GOSLING, Marlusa and XAVIER, Wescley Silva. Por trás do discurso socialmente responsável da siderurgia mineira. Prod. [online]. 2010, vol.20, n.3, pp.418-428. Epub Apr 02, 2010. ISSN 0103-6513. DOI: http://dx.doi.org/10.1590/S0103-65132010005000014.

AQUINO, W. de, SANTANA, A.C. de. Evidenciação. São Paulo. FIPECAFI, 1992.

BM\&FBOVESPA. BM\&FBOVESPA divulga a 12ª carteira do ISE - Índice de Sustentabilidade Empresarial. Disponível em: <http://www.b3.com.br/data/files/2B/A3/8F/1D/8DC98510EC7C8985790D8AA8/Carteira2017-\%20ISE-Portugues.pdf>. Acesso em: 12 novembro 2019.

BRAGATO, Ivelise Rasera; SIQUEIRA, Elisabete Stradiotto; GRAZIANO, Graziela Oste and SPERS, Eduardo Eugênio. Produção de açúcar e álcool vs. responsabilidade social corporativa: as ações desenvolvidas pelas usinas de cana-de-açúcar frente às externalidades negativas. Gest. Prod. [online]. 2008, vol.15, n.1, p. 89-100. ISSN 0104530X. DOI: http://dx.doi.org/10.1590/S0104-530X2008000100009.

BUFONI, André Luiz; MUNIZ, Natiara Penalva and FERREIRA, Aracéli Cristina de Sousa. $O$ processo de certificação socioambiental das empresas: 0 estudo de caso do certificado 'empresa cidadã'. Rev. adm. contemp. [online]. 2009, vol.13, n.spe, pp.19-38. ISSN 1415-6555. http://dx.doi.org/10.1590/S1415-65552009000500003.

BVSA, Bolsa De Valores Socioambientais. Tema. Disponível em: <https://www.bvsa.org.br/temas>. Acesso em: 08 de Setembro de 2018.

CALIXTO, Laura, BARBOSA, Ricardo, and Lima Marilene. Disseminação De Informações Ambientais Voluntárias: Relatórios Contábeis Versus Internet. Revista Contabilidade \& Finanças, vol. 18, n.spe, p. 84-95, 2007. DOI: https://doi.org/10.1590/S151970772007000300008 .

CAMPOS, Lucila Maria de Souza, SEHNEM, Simone, OLIVEIRA, Murilo de Alencar Souza, ROSSETTO, Adriana Marques, COELHO, Ana Lúcia de Araújo Lima, and DALFOVO, Michael Samir. Relatório de sustentabilidade: perfil das organizações brasileiras e estrangeiras segundo o padrão da Global Reporting Initiative. Gest. Prod. [online]. 2013, vol.20, n.4, pp.913-926. Epub Nov 26, 2013. ISSN 0104-530X. http://dx.doi.org/10.1590/S0104-530X2013005000013.

CARNEIRO, José Eliano, DE LUCA, Márcia Martins Mendes, and OLIVEIRA, Marcelle Colares. Análise Das Informações Ambientais Evidenciadas Nas Demonstrações Financeiras Das Empresas Petroquímicas Brasileiras Listadas Na Bovespa. Contabilidade Vista \& Revista, vol. 19, n. 3, jul./set., p. 39-67, 2008. Acessado novembro 12, 2018. https://revistas.face.ufmg.br/index.php/contabilidadevistaerevista/article/view/360. 
CLARO, Priscila Borin de Oliveira, CLARO, Danny Pimentel adn LUCCI, Cintia Retz. Responsabilidade Social: 0 Que os Futuros Administradores Entendem Sobre o Conceito? Organizações Rurais \& Agroindustriais, vol. 11, n. 2, p. 319-335, 2009. Acessado novembro 12, 2018. https://www.redalyc.org/articulo.oa?id=87812758004

COLARES, Ana Carolina Vasconcelos, BRESSAN, Valéria Gama Fully, LAMOUNIER, Wagner Moura and BORGES, Danilo Lacerda. O Balanço Social como indicativo socioambiental das empresas do Índice de Sustentabilidade Empresarial da BM\&Fbovespa. Revista de Contabilidade do Mestrado em Ciências Contábeis da UERJ, vol. 17, n. spe, p. 83-100, 2012. Acessado outubro 08, 2018. http://www.spell.org.br/documentos/ver/8904/obalanco-social-como-indicativo-socioambiental-das-empresas-do-indice-de-sustentabilidadeempresarial-da-bm-f-bovespa/i/pt-br

Deng, Xin \& Kang, Jun-koo \& Low, Buen Sin, 2013. Corporate social responsibility and stakeholder value maximization: Evidence from mergers. Journal of Financial Economics, Elsevier, vol. 110, n. 1, p. 87-109, 2013. DOI: 10.1016/j.jfineco.2013.04.014

DIEHL, A.A; TATIM, D. Pesquisa em ciências sociais aplicadas. São Paulo: Prentice Hall, 2004.

DOMENICO, Daniela Di, MAZZIONI, Sady, GUBIANI, Clésia Ana, KRONBAUER, Neli Bastezini and VILANI, Leonir. Práticas de Responsabilidade socioambiental nas empresas de capital aberto de Santa Catarina listadas na BM\&Fbovespa. Revista Catarinense da Ciência Contábil, v. 14, n. 42, p. 70-84, 2015. DOI:10.16930/2237-7662/rccc.v14n42p70-84

GALEGO-ALVAREZ, Isabel; FORMIGONI, Henrique and ANTUNES, Maria Thereza Pompa. Corporate social responsibility practices at brazilian firms. Rev. adm. empres. [online]. 2014, vol.54, n.1, p.12-27, 2014. DOI: http://dx.doi.org/10.1590/S0034759020140103.

IGARASHI, Deisy Cristina Corrêa, IGARASHI, Wagner, LIMA, Erimar Cleiton De, DALBELLO, Liliane and HERCOS JUNIOR, José Braz. Análise do alinhamento entre o balanço social e o relatório de sustentabilidade dos três maiores bancos em atividade no Brasil. Revista ConTexto. Porto Alegre, Vol. 10, n. 18, p. 34-48, 2010. Acessado agosto 15 , 2018. http://www.spell.org.br/documentos/ver/47664/analise-do-alinhamento-entre-obalanco-social-e-o-relatorio-de-sustentabilidade-dos-tres-maiores-bancos-em-atividade-nobrasil/i/pt-br

ISE, Índice de Sustentabilidade Empresarial. 0 que é o ISE. Disponível em: <https://iseb3.com.br/o-que-e-o-ise>. Acesso em: 12/11/ 2019.

KARKOTLI, G.; ARAGÃO, S.D. Responsabilidade Social - uma contribuição à gestão transformadora das organizações. $2^{\underline{a}}$ ed. Petrópolis: Vozes, 2005.

LANA, Cássio Afonso Medeiros, BERNARDO, Denise Carneiro dos Reis, NAZARETH, Luiz Gustavo Camarano and MENDONÇA, Fabrício Molica. Um estudo das ações para divulgar e consolidar o Balanço Social no Brasil. Revista Gestão Organizacional, vol.4, n. 2, p. 311-329, 2011. DOI: http://dx.doi.org/10.22277/rgo.v4i2.895

MACEDO, Marcelo Alvaro da Silva, CÍPOLA, Fabrício Carvalho. Análise do desempenho socioambiental no setor siderúrgico brasileiro. Revista de Contabilidade e Organizações, vol. 3, n.7, p. 60-77, 2009. DOI: https://doi.org/10.11606/rco.v3i7.34750.

MILANI FILHO, Marco Antonio Figueiredo. Responsabilidade social e investimento social privado: entre o discurso e a evidenciação. Rev. contab. finanç. [online]. 2008, vol.19, n.47, pp.89-101. ISSN 1519-7077. http://dx.doi.org/10.1590/S1519-70772008000200008. 
NEU, Dean, WARSAME, Hussain A. and PEDWELL Kathryn. Managing Public Impressions: Environmental Disclosures in Annual Reports. Accounting, Organizations and Society, vol. 23, n. 3, p. 265-282, 1998. DOI: https://doi.org/10.1016/S0361-3682(97)00008-1

OLIVEIRA, Braulio and GOUVEA, Maria Aparecida. A importância das ações sociais empresariais nas decisões de compra dos consumidores. Gest. Prod. [online]. 2010, vol.17, n.4, p. 791-800. ISSN 0104-530X. http://dx.doi.org/10.1590/S0104$530 \times 2010000400012$.

OLIVEIRA, Isaac Gezer Silva de and CARDOSO, Sâmela Pedrada. Responsabilidade Socioambiental e Sustentabilidade Empresarial: uma análise empírica em empresas listadas na Bm\&Fbovespa. In: CONGRESSO UFSC DE INICIAÇÃO CIENTÍFICA EM CONTABILIDADE, 6., Florianópolis, 2015. Anais... Florianópolis, 2015. 6ํㅡ Congresso UFSC De Iniciação Científica Em Contabilidade, UFSC, 2015.

OLIVEIRA, José Antônio Puppim de. Uma avaliação dos balanços sociais das $\mathbf{5 0 0}$ maiores. RAE electron. [online], vol.4, n.1, 2005. DOI: http://dx.doi.org/10.1590/S167656482005000100002 .

ORELLANO, Verônica Ines Fernandez and QUIOTA, Silvia. Análise do retorno dos investimentos socioambientais das empresas brasileiras. Rev. adm. empres. [online]. 2011, vol.51, n.5, pp.471-484. ISSN 0034-7590. http://dx.doi.org/10.1590/S003475902011000500005 .

PASTRANA, Nathaly Aya and SRIRAMESH, Krishnamurthy. Corporate Social Responsibility: Perceptions and practices among SMEs in Colombia. Public Relations Review. vol. 40, p. 14 - 24. 2014. ISSN : 0363-8111, DOI: 10.1016/j.pubrev.2013.10.002

PINTO, Anacleto Laurino and RIBEIRO, Maisa de Souza. Balanço social: avaliação de informações fornecidas por empresas industriais situadas no estado de Santa Catarina. Rev. contab. finanç., São Paulo, vol. 15, n. 36, p. 21-34, Dez. $2004 . \quad$ DOI: https://doi.org/10.1590/S1519-70772004000300002

PINTO, Marcelo de Rezende and LARA, José Edson. A cidadania corporativa como uma orientação de marketing: um estudo no varejo. Rev. adm. Empres., São Paulo, vol.44, n. spe, p. 48-60, Dez. 2003. DOI: http://dx.doi.org/10.1590/S0034-75902004000500004

SANTOLIN, Adriano Domingues and FREY, Márcia Rosane. O papel do balanço social na gestão empresarial. Contabilidade. Vista \& Revista, Belo Horizonte, vol. 16, n. 2, p.61-81, $\begin{array}{lllll}\text { ago. } 2005 . & \text { Acessado novembro } & 12, & 2018 .\end{array}$ https://revistas.face.ufmg.br/index.php/contabilidadevistaerevista/article/view/278.

SOUSA FILHO, José Milton de and WANDERLEY, Lilian Soares Outttes. Divulgação da responsabilidade social empresarial: como os websites empresariais vêm sendo utilizados por empresas de energia e varejo. Cad. EBAPE.BR [online]. 2007, vol.5, n.2, p.0113. ISSN 1679-3951. http://dx.doi.org/10.1590/S1679-39512007000200008.

TREVISAN, Fernando Augusto. Balanço social como instrumento de marketing. RAEeletrônica, São Paulo, vol.1, n. 2, p.1-12, 2002.

TRIVIÑOS, A.N. Introdução à pesquisa em ciências sociais: a pesquisa qualitativa em educação. São Paulo: Atlas, 1987.

Fundo de Financiamento - "O presente trabalho foi realizado com apoio da Coordenação de Aperfeiçoamento de Pessoal de Nível Superior - Brasil (CAPES) - Código de Financiamento 001 